\title{
CHARACTERIZATION OF PATIENT SAFETY INCIDENTS REPORTED BY PATIENTS OR FAMILIES TO THE BRAZILIAN HEALTH REGULATORY SYSTEM - $2014-2019$
}

\author{
Heiko Thereza Santana ${ }^{1,}$, Magda Machado de Miranda Costa1, Maria Dolores Santos da \\ Purificação Nogueira1, Ana Clara Ribeiro Bello dos Santos ${ }^{1}$, André Anderson Carvalho' ${ }^{1}$, Cleide \\ Felicia de Mesquita Ribeiro1, Humberto Luiz Couto Amaral de Moura1, Lilian de Souza Barros', \\ Luciana Silva da Cruz de Oliveira1, Mara Rubia Santos Gonçalves ${ }^{1}$, Andressa Honorato Miranda \\ de Amorim ${ }^{1}$, Silvano Barbosa de Oliveira ${ }^{2}$ and Fernanda Raphael Escobar Gimenes de Sousa ${ }^{3}$
}

1Management of Health Services Surveillance and Monitoring (GVIMS), General Management of Health Services Technology (GGTES), Brazilian Health Regulatory Agency (ANVISA), Brasilia, Brazil

${ }^{2}$ Ministry of Health (Brazil), Brasilia, Brazil

3Department of General and Specialized Nursing - University of São Paulo at Ribeirão Preto, College of Nursing, São Paulo, Brazil

\section{ARTICLE INFO}

\section{Article History}

Received $25^{\text {th }}$ January, 2021

Received in revised form

$17^{\text {th }}$ January, 2021

Accepted $20^{\text {th }}$ February, 2021

Published online $30^{\text {th }}$ March, 2021

Key Words:

Adverse Events, Health Services, Incident Reporting, Patient-Centered Care, Patient Engagement, Patient Safety, Sanitary Surveillance.

*Corresponding author: Heiko Thereza Santana

\begin{abstract}
Patient safety incidents, especially adverse events (AEs), are a global public health issue. The objective of the study was to characterize patient safety incidents reported by patients or families to the Brazilian Health Regulatory System (SNVS). This is a descriptive, retrospective study with a quantitative approach, using a database from the Brazilian Health Regulatory Agency (ANVISA), NOTIVISA - Citizen module, 2014 to 2019. A total of 1355 safety incident were reported, a majority from the Southeast region (45.3\%), occurred more frequently among women $(58.0 \%)$ aged between 26 and $35(16.7 \%)$ and 56 and 65 years (16.5\%). Healthcare-associated infections (HAIs) (36.3\%) were the most frequently notified event, followed by medication/intravenous fluid (IV) incident (36.2\%). Injury was mostly classified as mild (32.0\%) and moderate $(23.7 \%)$. From a total of 33 deaths, the majority $(51.5 \%)$ were due to HAI. There was a significant association between the proportion of deaths and age group ( $\mathrm{p}$-value $=0.032$ ). Most notifications were related to HAIs, followed by drugs or IV fluids and most reported incidents resulting in death were due to HAIs, with a significant difference observed in the proportion of deaths in relation to age group. The study demonstrates the need for greater encouragement and participation of patients and family members in reporting incidents, valuing their experiences for continuous learning from errors in health services.
\end{abstract}

Copyright (C) 2021, Heiko Thereza Santana et al. This is an open access article distributed under the Creative Commons Attribution License, which permits unrestricted use, distribution, and reproduction in any medium, provided the original work is properly cited.

Citation: Heiko Thereza Santana, Magda Machado de Miranda Costa, Maria Dolores Santos da Purificação Nogueira et al. "Characterization of patient safety incidents reported by patients or families to the Brazilian Health Regulatory System - 2014 - 2019”, International Journal of Development Research, $11,(03), 45655-45661$

\section{INTRODUCTION}

Patientsafety incidents, especially adverse events (AEs), are a global public health issue requiring corrective and preventive action to minimize injury to patients (WHO, 2021). About $10 \%$ of patients in health services are affected by AEs, resulting in thousands of deaths annually, with $1 \%$ suffering serious consequences. Half of these events are subject to preventive measures (Baker et al., 2004; WHO, capable of avoiding unnecessary suffering andpreserving the economy of households, health care, society and the state. In this context, patient safety is an essential component of quality management, and should be considered a fundamental principle of patient-centered care (WHO, 2002). Efforts should also be made to learn from mistakes, based on a safety culture that involves professionals, organizations and patients (IOM, 2001). Since 2004, the World Health Organization (WHO) has been leading the global movement for patient safetv and ensuring a voice for usersof health 
been systematically developed by the Brazilian Health Regulatory Agency (ANVISA) (Santana et al., 2020), having been reinforced in 2013 with the guidelines established by the National Patient Safety Program (PNSP) (Brasil, 2013a).Following recommendations by the WHO and considering that "a patient more engagedin their ownhealth care can help prevent safety incidents", the Ministry of Healthincluded the parameter"Involvement of citizens in their safety" (Brasil, 2013b) in the PNSP (Brasil, 2013a). However, since 2011, health services have been expectedto establish best practices and implement actions to promote patient participation in the care provided (Brasil, 2011). In 2013, it was reinforced that Patient Safety Centers (NSPs) should encourage the participation of patients and family members in all levels of care (Brasil, 2013c).

An additional precaution adopted by the Brazilian Health Regulatory System (SNVS) was to support the participation of patients and family members in the voluntary safety incident reporting process (Notivisa, 2021a). It is known that patients hold a unique position, being able to contribute to the safety improvement of health systems by sharing information about safety issues they have experienced in health services and reporting incidents in local or national information systems (Ward et al., 2011; EC, 2010). Several studies have shown that patients and families can provide experiences and expertise that are useful, andpossiblyrich learning opportunities from errors and improvements in health care (Longtin et al., 2010; Khan et al., 2018). Nevertheless, there are few studies documenting the analysis of safety incidents reported by patients and family members in different countries. In Brazil, despite the topic's relevance, there are also knowledge gaps in this field and studies remain scarce, requiring research that discloses the results of incident reports made by citizens. As a result, there was an interest in investigating how the main safety incidents reported by Brazilian citizens are characterized. The objective of the study was to characterize patient safety incidents reported by patients and family members to the SNVS in the period between March 2014 and December 2019. Secondary objectives include: assessing associations between safety incidents and explanatory variables (sex, age group, race, geographic region, number of cases per year, phase of care, place and period of occurrence of the event) and evaluating associations between deaths and other explanatory variables (sex, age group, race, geographic region, period of occurrence and detection of the event).

\section{METHODS}

Study design and duration: This is a descriptive, retrospective study following a quantitative approach. The data used in the study are secondary, obtained from a national database (NOTIVISA, Citizen Module) and include safety incidents reported by patients or relatives to the SNVSbetween March 2014 and December 2019.

Population and data collection: Safety incident reports to the SNVSwere made by hospitalized or not hospitalized patients (or family members) who receivedcare / treatment by health servicesin the country, since the national implementation of NOTIVISA (Citizen Module). These incident records were included in the study.

Data analysis: The following variables of interest were analyzed to characterize the incidents reported: year of report, geographic region, sex, age group, race / color, phase of care, place and period of occurrence of the event, detection, and injury severity (Notivisa, 2021a). Taking into consideration the most frequently reported incidents, grouping was done into four main categories: 1) Health care-related infections - HAIs; 2) Incidents related to medications or intravenous fluids (IV); 3) Incidents related to clinical process or procedure (procedure / treatment / intervention; diagnosis / evaluation; complementary diagnostic); medical errors / failure to protect (evasion, accident, fall and pressure ulcers) and other incidents that occurred during surgical procedure; and 4) Incidents related to clinical administration (admission; discharge; transfer; scheduling of appointments; resources and organizational management; documentation; patient identification; and infrastructure
/ facilities). Incidents reported as "other" have been reclassified, when possible, considering the specific incident options available on the notification form. Exclusion criteria adopted were: lack of information / incomplete form, adverse reaction to drugs and vaccines, technical complaints, therapeutic ineffectiveness and when not applicable (did not characterize an incident). Descriptive statistics were used, and aggregate data analysis was conducted. It was therefore not possible to identify the source of information, maintaining confidentiality of the reporting citizen's data in accordance with ANVISA requirements. For association analysis between the type of incident and variables of interest (sex, age group, race, geographic region, number of cases per year, phase of care, place and period of occurrence of the event) and the event of death and variables of interest (sex, age group, race, geographic region, place and period of occurrence of the event, and detection), p-value was calculated using the chi-square test. The confidence interval (CI) was $95 \%$ and a $5 \%$ significance level $(\alpha=0.05)$ was considered in all analyses. Treatment and analysis of data were performed using Stata version 16 statistical software.

\section{RESULTS}

A total of 1355 safety incident reports by patients and family members were registered during the analysis period. In general, it was found that a majority originated from the Southeast region $(45.3 \%)$, occurred more frequently among women $(58.0 \%)$ aged between 26 and $35(16.7 \%)$ and 56 and 65 years $(16.5 \%)$, and belonging to the white race, as shown in Table 1 . Most incidents occurred during provision of care $(35.5 \%)$ and when the patient was not hospitalized (31.2\%). The type of health service where most incidents took place was the hospital $(38.2 \%)$. Incident rate was higher during daytime $(61.0 \%)$. With respect toadverse event detection, patients and family members reported that they were informed by health professionals $(64.4 \%)$. The types of incidents reported were HAIs $(36.3 \%)$, followed by incidents related to IV fluids or medications $(36.2 \%)$, clinical process / procedure (16.1\%) and clinical administration (11.4\%).In general, injury was mostly classified as mild (32.0\%) and moderate (23.7\%). Grouped frequency distribution of incidents was statistically different in relation to all variables studied ( $p$-value $<0.001$ ) (Table 1). Evaluation of reports over the years shows a tendency for the number of reported events to increase, exceptfor 2017, which displayed a decrease in incidents. In 2018 and 2019, 420 event notifications were made each year. In 2018,most incident reports were associated withmedications or IV fluids, totaling 200 cases and comprising approximately $50.0 \%$ of all notifications. In 2019 , there was a decrease in the reporting of these incidents, but an increase in HAIs notifications (55.5\%) (Table 1).

A higher percentage of incident reports related to medications or IV fluids was observed in all geographic locations excluding the Southeast region, where more HAIs cases were reported $(48.5 \%)$. With respect to the most frequently reported incident categories and sex, men were more affected by HAIs (40.1\%), while events involving medications or IV fluids were mostly described in women $(40.5 \%)$. As for the degree of harm, higher percentages of mild $(35.3 \%)$, moderate $(47.5 \%)$, and severe $(42.5 \%)$ injury were seen in notifications related to medications or IV fluids (Table 1).Among the reported events that resulted in deaths, $17(51.5 \%)$ were due to HAIs, $11(33.3 \%)$ resulted from clinical process / procedure and $5(15.2 \%)$ were associated with medications or IV fluids, totaling 33 deaths (Table 1). Taking proportion into consideration, the results also show that the majority of death reports came from the Midwest region $(4.8 \%)$, followed by the Northeast $(2.6 \%)$,and occurred mostly among men (3.2\%) aged 65 and older (4.3\%) belonging to the Asian race $(16.0 \%)$. Although daytime was the period with thegreatest number of incident notifications, deaths were more frequently reported at night (3.8\%). In regard to detection and disclosureof the event to patients and family members, a majority of patients answered "I am not sure" $(5.3 \%)$. There were no statistically significant differences in the proportion of deaths in relation to year, sex, period, and detection. 
Table 1. Distribution of incidents according to patient and incident characteristics

\section{Brazil, 2014 to 2019}

\begin{tabular}{|c|c|c|c|c|c|c|c|c|c|c|}
\hline \multirow{2}{*}{ Variables } & \multirow{2}{*}{$\frac{\text { Total }}{\mathrm{n}}$} & \multicolumn{2}{|c|}{ Clinical Administration } & \multicolumn{2}{|c|}{ Medication/IVfluids } & \multicolumn{2}{|c|}{ Process/clinical procedure } & \multicolumn{2}{|c|}{ HAIs } & \multirow{2}{*}{ p-value* } \\
\hline & & $\mathrm{n}$ & $\%$ & $\mathrm{n}$ & $\%$ & $\mathrm{n}$ & $\%$ & $\mathrm{n}$ & $\%$ & \\
\hline Total & 1355 & 154 & 11.4 & 491 & 36.2 & 218 & 16.1 & 492 & 36.3 & - \\
\hline \multicolumn{11}{|l|}{ Year } \\
\hline 2014 & 84 & 3 & 3.6 & 55 & 65.5 & 11 & 13.1 & 15 & 17.9 & \multirow{6}{*}{$<0.001$} \\
\hline 2015 & 110 & 12 & 10.9 & 40 & 36.4 & 24 & 21.8 & 34 & 30.9 & \\
\hline 2016 & 218 & 30 & 13.8 & 92 & 42.2 & 38 & 17.4 & 58 & 26.6 & \\
\hline 2017 & 103 & 16 & 15.5 & 40 & 38.8 & 14 & 13.6 & 33 & 32.0 & \\
\hline 2018 & 420 & 41 & 9.8 & 200 & 47.6 & 60 & 14.3 & 119 & 28.3 & \\
\hline 2019 & 420 & 52 & 12.4 & 64 & 15.2 & 71 & 16.9 & 233 & 55.5 & \\
\hline \multicolumn{11}{|l|}{ Geographic region } \\
\hline North & 63 & 9 & 14.3 & 31 & 49.2 & 9 & 14.3 & 14 & 22.2 & \multirow{5}{*}{$<0.001$} \\
\hline Northeast & 269 & 38 & 14.1 & 110 & 40.9 & 47 & 17.5 & 74 & 27.5 & \\
\hline Southeast & 614 & 57 & 9.3 & 190 & 30.9 & 69 & 11.2 & 298 & 48.5 & \\
\hline South & 220 & 33 & 15.0 & 95 & 43.2 & 35 & 15.9 & 57 & 25.9 & \\
\hline Midwest & 189 & 17 & 9.0 & 65 & 34.4 & 58 & 30.7 & 49 & 25.9 & \\
\hline \multicolumn{11}{|l|}{ Sex } \\
\hline Male & 569 & 57 & 10.0 & 173 & 30.4 & 111 & 19.5 & 228 & 40.1 & \multirow{2}{*}{$<0.001$} \\
\hline Female & 786 & 97 & 12.3 & 318 & 40.5 & 107 & 13.6 & 264 & 33.6 & \\
\hline \multicolumn{11}{|l|}{ Age group } \\
\hline younger than 29 days & 58 & 13 & 22.4 & 12 & 20.7 & 11 & 19.0 & 22 & 37.9 & \multirow{13}{*}{$<0.001$} \\
\hline 29 daysto 1 year & 34 & 4 & 11.8 & 11 & 32.4 & 9 & 26.5 & 10 & 29.4 & \\
\hline 2 to 4 years & 21 & 3 & 14.3 & 12 & 57.1 & 2 & 9.5 & 4 & 19.0 & \\
\hline 5 to 11 years & 35 & 9 & 25.7 & 9 & 25.7 & 4 & 11.4 & 13 & 37.1 & \\
\hline 12 to 17 years & 22 & 2 & 9.1 & 13 & 59.1 & 2 & 9.1 & 5 & 22.7 & \\
\hline 18 to 25 years & 146 & 14 & 9.6 & 91 & 62.3 & 8 & 5.5 & 33 & 22.6 & \\
\hline 26 to 35 years & 226 & 24 & 10.6 & 101 & 44.7 & 14 & 6.2 & 87 & 38.5 & \\
\hline 36 to 45 years & 189 & 27 & 14.3 & 67 & 35.4 & 27 & 14.3 & 68 & 36.0 & \\
\hline 46 to 55 years & 147 & 14 & 9.5 & 46 & 31.3 & 21 & 14.3 & 66 & 44.9 & \\
\hline 56 to 65 years & 224 & 22 & 9.8 & 70 & 31.3 & 32 & 14.3 & 100 & 44.6 & \\
\hline 66 to 75 years & 123 & 9 & 7.3 & 33 & 26.8 & 37 & 30.1 & 44 & 35.8 & \\
\hline 76 to 85 years & 101 & 9 & 8.9 & 24 & 23.8 & 38 & 37.6 & 30 & 29.7 & \\
\hline Over 85 years & 29 & 4 & 13.8 & 2 & 6.9 & 13 & 44.8 & 10 & 34.5 & \\
\hline \multicolumn{11}{|l|}{ Race } \\
\hline White & 713 & 82 & 11.5 & 299 & 41.9 & 98 & 13.7 & 234 & 32.8 & \multirow{6}{*}{$<0.001$} \\
\hline Black & 101 & 9 & 8.9 & 19 & 18.8 & 18 & 17.8 & 55 & 54.5 & \\
\hline Brown & 360 & 34 & 9.4 & 120 & 33.3 & 64 & 17.8 & 142 & 39.4 & \\
\hline Asian & 25 & 3 & 12.0 & 7 & 28.0 & 8 & 32.0 & 7 & 28.0 & \\
\hline Indigenous & 4 & 1 & 25.0 & 1 & 25.0 & 1 & 25.0 & 1 & 25.0 & \\
\hline Not informed & 152 & 25 & 16.4 & 45 & 29.6 & 29 & 19.1 & 53 & 34.9 & \\
\hline Phaseof Care & & & & & & & & & & \\
\hline
\end{tabular}




\begin{tabular}{|c|c|c|c|c|c|c|c|c|c|c|}
\hline During the diagnostic phase/assessment & 270 & 26 & 9.6 & 57 & 21.1 & 43 & 15.9 & 144 & 53.3 & \multirow{8}{*}{$<0.001$} \\
\hline Assistance/treatment & 481 & 39 & 8.1 & 108 & 22.5 & 132 & 27.4 & 202 & 42.0 & \\
\hline During or after blood donation & 5 & 0 & 0.0 & 0 & 0.0 & 5 & 100.0 & 0 & 0.0 & \\
\hline Admission & 120 & 50 & 41.7 & 23 & 19.2 & 18 & 15.0 & 29 & 24.2 & \\
\hline Discharge & 18 & 1 & 5.6 & 4 & 22.2 & 9 & 50.0 & 4 & 22.2 & \\
\hline Transfer of care & 10 & 6 & 60.0 & 0 & 0.0 & 0 & 0.0 & 4 & 40.0 & \\
\hline Patient was not hospitalized & 423 & 28 & 6.6 & 287 & 67.8 & 10 & 2.4 & 98 & 23.2 & \\
\hline Post-discharge & 28 & 4 & 14.3 & 12 & 42.9 & 1 & 3.6 & 11 & 39.3 & \\
\hline \multicolumn{10}{|l|}{ Care Setting } & \multirow{13}{*}{$<0.001$} \\
\hline Ambulatory & 202 & 15 & 7.4 & 25 & 12.4 & 10 & 5.0 & 152 & 75.2 & \\
\hline Blood bank/Hemotherapy Service & 2 & 0 & 0.0 & 0 & 0.0 & 2 & 100.0 & 0 & 0.0 & \\
\hline Health Center & 65 & 12 & 18.5 & 23 & 35.4 & 4 & 6.2 & 26 & 40.0 & \\
\hline PharmacyDrug Store & 65 & 3 & 4.6 & 43 & 66.2 & 1 & 1.5 & 18 & 27.7 & \\
\hline Outside health care/other & 364 & 34 & 9.3 & 255 & 70.1 & 9 & 2.5 & 66 & 18.1 & \\
\hline Hospital & 517 & 54 & 10.4 & 91 & 17.6 & 180 & 34.8 & 192 & 37.1 & \\
\hline Clinical Laboratory & 18 & 11 & 61.1 & 2 & 11.1 & 1 & 5.6 & 4 & 22.2 & \\
\hline Nuclear Medicine & 38 & 6 & 15.8 & 28 & 73.7 & 2 & 5.3 & 2 & 5.3 & \\
\hline Radiology Service & 18 & 3 & 16.7 & 4 & 22.2 & 4 & 22.2 & 7 & 3.9 & \\
\hline Urgent and Emergency Service & 47 & 13 & 27.7 & 17 & 36.2 & 3 & 6.4 & 14 & 29.8 & \\
\hline Hemodialysis Services & 15 & 1 & 6.7 & 1 & 6.7 & 2 & 13.3 & 11 & 73.3 & \\
\hline Mental Health Services or Institutions & 4 & 2 & 50.0 & 2 & 50.0 & 0 & 0.0 & 0 & 0.0 & \\
\hline \multicolumn{11}{|l|}{ Period } \\
\hline During the day & 827 & 103 & 12.5 & 252 & 30.5 & 127 & 15.4 & 345 & 41.7 & \multirow{3}{*}{$<0.001$} \\
\hline At night & 234 & 26 & 11.1 & 92 & 39.3 & 52 & 22.2 & 64 & 27.4 & \\
\hline Patient was not able to inform & 294 & 25 & 8.5 & 147 & 50.0 & 39 & 13.3 & 83 & 28.2 & \\
\hline \multicolumn{11}{|l|}{ Detection } \\
\hline Yes & 873 & 84 & 9.6 & 266 & 30.5 & 175 & 20.0 & 348 & 39.9 & \multirow{3}{*}{$<0.001$} \\
\hline No & 369 & 53 & 14.4 & 174 & 47.2 & 34 & 9.2 & 108 & 29.3 & \\
\hline ...I am not sure & 113 & 17 & 15.0 & 51 & 45.1 & 9 & 8.0 & 36 & 31.9 & \\
\hline \multicolumn{11}{|l|}{ Degree of harm } \\
\hline None & 265 & 28 & 10.6 & 52 & 19.6 & 33 & 12.5 & 152 & 57.4 & \multirow{5}{*}{$<0.001$} \\
\hline Mild & 434 & 51 & 11.8 & 153 & 35.3 & 82 & 18.9 & 148 & 34.1 & \\
\hline Moderate & 322 & 26 & 8.1 & 153 & 47.5 & 48 & 14.9 & 95 & 29.5 & \\
\hline Severe & 301 & 49 & 16.3 & 128 & 42.5 & 44 & 14.6 & 80 & 26.6 & \\
\hline Death & 33 & 0 & 0.0 & 5 & 15.2 & 11 & 33.3 & 17 & 51.5 & \\
\hline
\end{tabular}

p-value of the chi-square test Source: NOTIVISA/ANVISA - Citizen Module (Mar/2014 to Dec/2019). Abbreviations: IV, intravenous fluids; HAIs: Health care-related infections. 
Table 2. Distribution of incidents according to patient and incident characteristics Brazil, 2014 to 2019

\begin{tabular}{|c|c|c|c|c|}
\hline \multirow[t]{2}{*}{ Variable } & \multirow{2}{*}{$\frac{\text { Total }}{\mathrm{n}}$} & \multicolumn{2}{|c|}{ Death } & \multirow[t]{2}{*}{ p-value* } \\
\hline & & $\mathrm{n}$ & $\%$ & \\
\hline Total & 1355 & 33 & 2.4 & - \\
\hline \multicolumn{5}{|l|}{ Geographicregion } \\
\hline North & 63 & 0 & 0.0 & \multirow[t]{5}{*}{0.114} \\
\hline Northeast & 269 & 7 & 2.6 & \\
\hline Southeast & 614 & 15 & 2.4 & \\
\hline South & 220 & 2 & 0.9 & \\
\hline Midwest & 189 & 9 & 4.8 & \\
\hline \multicolumn{5}{|l|}{ Sex } \\
\hline Male & 569 & 18 & 3.2 & \multirow[t]{2}{*}{0.139} \\
\hline Female & 786 & 15 & 1.9 & \\
\hline \multicolumn{5}{|l|}{ Age group } \\
\hline Up to 17 years & 112 & 4 & 3.6 & \multirow[t]{3}{*}{0.032} \\
\hline From 18 to 65 years & 932 & 16 & 1.7 & \\
\hline Over 65 years & 253 & 11 & 4.3 & \\
\hline \multicolumn{5}{|l|}{ Race } \\
\hline White & 713 & 14 & 2.0 & \multirow[t]{5}{*}{0.028} \\
\hline Black & 101 & 2 & 2.0 & \\
\hline Brown & 360 & 10 & 2.8 & \\
\hline Asian & 25 & 4 & 16.0 & \\
\hline Indigenous & 4 & 0 & 0.0 & \\
\hline \multicolumn{5}{|l|}{ Period } \\
\hline During the day & 827 & 16 & 1.9 & \multirow[t]{3}{*}{0.231} \\
\hline At night & 234 & 9 & 3.8 & \\
\hline Patient was not able to inform & 294 & 8 & 2.7 & \\
\hline \multicolumn{5}{|l|}{ Detection } \\
\hline Yes & 873 & 17 & 1.9 & \multirow[t]{3}{*}{0.078} \\
\hline No & 369 & 10 & 2.7 & \\
\hline I am not sure & 113 & 6 & 5.3 & \\
\hline
\end{tabular}

There was a significant association between the proportion of deaths andage group $(\mathrm{p}$-value $=0.032)$ as well asrace $/$ color $(\mathrm{p}$-value $=$ 0.028 ) variables, as shown in Table 2.

\section{DISCUSSION}

The present study characterizes safety incidents notified to the SNVS from 2014 to 2019 -being significant forproviding a general distribution analysis of incidents reported by patients and family members. A majority of incidents occurred in the hospital (about $40 \%$ ), which is consistent with most findings showing a higher occurrence of events in these institutions, due to high care-associated risks and better documentation of safety improvement strategies (WHO, 2002). An analysis of notifications made to the Incident Report Resulting from Medical Error system in Mexico revealed that $84 \%$ of reported events occurred in hospitals (Rodríguez-Suárez et al., 2012a). The study's findings showed that incidents occurred primarily among women $(58.0 \%$ ) of working age (26 to $35-16.7 \%$ and 56 to 65 years $-16.5 \%$ ). In Mexico, incidents also occurred more in women $(2: 1$ ratio) and notifications increased with patient age. Nevertheless, approximately 64 to $74 \%$ of events happened with people aged 18 to 65 years (Rodríguez-Suárez et al., 2012a). As for the fact that most incidents occurred during the day, this may be due to routine practices in health institutions, where procedures performed by health care professionals are mainly conducted during this period, possibly leading to adverse events if patient safety practices are not adopted (Shojania et al, 2001). In regard to types of incidents most frequently reported, HAIs predominated, similar to other studies (EC, 2010; Rodríguez-Suarez et al., 2012b), since they affect hospitalized patients worldwide (Flanagan et al., 2011; WHO, 2011a; WHO, 2009b). A study carried out between 2011 and 2012, involving 781 events reported voluntarily by 22 Mexican hospitals through the Automated Registration System of Health Incidents (SIRAIS), based on the International Classification for Patient Safety (WHO\& WHO Patient Safety, 2010), showed that HAIs were the most frequently disclosed incident $(35.9 \%)$, followed by those related to clinical process / procedure $(28.8 \%)$, and medication / IV fluids $(12.5 \%)$ (Rodríguez-Suarez et al., 2012b).
Another study showed that HAIs were reported by $8.2 \%$ of hospitalized patients (Agoritsas et al., 2005). Evidently, HAIs are a challenge for health services around the world. It is estimated that more than 4 million patients in Europe and 1.7 million in the United States annually develop some type of HAIs, with higher prevalence in low- and middle-income countries. However, approximately 20 to $30 \%$ of HAIs can be avoided with the implementation of control and prevention measures in health care facilities, including adherence to standard precaution by health care workers, such as hand hygiene, epidemiological surveillance of HAIs (Central Line-associated Bloodstream Infection - CLABSI, Catheter-associated Urinary Tract Infections - CAUTI, Surgical Site Infection - SSI and Ventilatorassociated Pneumonia - VAP), implementation of antibiotic stewardship programs, cleaning, disinfection, and sterilization of medical equipment, and cleaning environmental (Brasil, 1998; WHO, 2009b; WHO, 2016a; ANVISA, 2017).

The second most recurrent type of incident involved medications or IV fluids, a finding that supports several studies (Weingart et al., 2005; Hasegawa et al., 2011; Harrison et al., 2015; O'Hara et al., 2018). Patients seem to report more medication-related safety incidents than any other category (Ward, Armitage, 2012). For instance, a study found that $71 \%$ of events reported by patients were medication errors (Weingart et al., 2005). Two other studies showed that patients reported medication-associated problems in 33 and $39 \%$ of cases, respectively (Hasegawa et al., 2011;Friedman et al., 2008). In addition, one in ten patients admitted to English hospitals disclosed at least one incident involving medication (O'Hara et al., 2018). Such events can be avoided throughout the medication-use system (prescription, dispensing/distribution, preparation/administration and monitoring) (WHO, 2016b), with multidisciplinary work by medical, nursing, and pharmaceutical teams (Keers et al., 2014; Goedecke et al., 2016; Janmano et al., 2018; Cohen, Smetzer, 2018). Incidents reported by patients using medications are known to support the identification of new events not previously notified by health professionals to regulatory agencies (Harmark et al., 2015; Aslani et al., 2018). However, health care teams have not routinely asked patients to report incidents that may have occurred during care (Harrison et al., 2015). 
The number of incidents reported by citizens has increased over the study period, the Southeast region being responsible for most notifications - possibly for having the greatest concentration of health services in the country. Nevertheless, despite a reporting system made available by ANVISA, the number of notifications remains low. A study conducted in 2009, involving $27 \mathrm{EU}$ member countries, showed that 7,031 interviewed citizens claimed to have been affected by AEs when hospitalized, although $70 \%$ did not report these events (EC, 2010). In regard to incident detection, patients and family members reported that they were informed by health professionals in most cases $(64.4 \%)$. By contrast, approximately 70 to $90 \%$ of AEs that occurred in Mexico were not communicated to patients or their families (Rodríguez-Suárez et al., 2012a). Traditionally, health professionals have avoided discussing safety incidents with patients and family members, partly due to fear of legal proceedings for negligence and embarrassment or discomfort communicating the event (AHRQ, PSNet, 2021). Hence, the importance of transparent and timely communication surrounding incidents in improving patient and family confidence in health care. From this perspective, the Canadian Patient Safety Institute has developed guidelines that symbolize a commitment to patients' right to be informed if they are involved in a patient safety incident. Such guidelines promote a clear and consistent approach to communication of the event, emphasizing the importance of teamwork and continuous learning (CPSI, 2011). As for the 33 notifications of death due to AEs, significant differences were found in the proportion of deaths in relation to age group (pvalue $=0.032$ ). It is well documented that the incidence of AEs increases with age, with patients aged 65 years and over having twice the risk of suffering some type of AE compared to those aged 16 to 44 years, with no difference between the sexes. The degree of injury caused by AEs depends on several factors and may even affect patient mortality, requiring preventive action by health services, given that $40 \%$ of AEs can be avoided (Villanueva-Egan et al., 2012). A secondary study, using ANVISA's database with respect to NOTIVISA registered reports (Health Care module), showed that 417 AE-related deaths were recorded by health professionals from 2014 to 2016 , mostly in young and older adults $(85 \%)$, with no differences between sexes.

Incident notification is a strategy to mobilize patients for their own protection and encourages them to share safety problems. However, patients may assume their reporting will not result in any satisfactory response, thus potentially omitting disclosure (Rodríguez-Suárez et al., 2012a). In the SNVS system, notifications are not analyzed individually, avoiding the punishment of those involved. Nevertheless, according to ANVISA, the information gathered is used to institute general preventive measures and reduce future harm to patients using the country's health services (Brasil, 2017). Patients are an important source of learning, but still neglected in determining and assessing the quality and safety of health care (O'Hara et al., 2018). In its Global Patient Safety Action Plan, the WHO reinforced the importance of citizen involvement and empowerment for the strengthening of health systems and the provision of safer care free of preventable injury (WHO, 2020). However, several barriers hinder patient empowerment and engagement in safety initiatives, such as inadequate infrastructure for quality management, excessive organizational hierarchy in health institutions, communication difficulties and the discredited information reported by patients. Therefore, patient involvement should be encouraged at all levels of health care (Saturno, 2009). To enable the effective and timely participation of citizens in the notification process, it is necessary for them to understand the definition of incidents, feel motivated to report, and most importantly, be aware of available reporting systems (Aslani et al., 2018). However, systems must have forms that contain terminology that is understandable to patients, yet also reflect prevailing patient safety language (WHO\& WHO Patient Safety, 2010; Larizgoitia et al., 2013), in order to improve event reporting and optimize its use in health care. Sharing results from the analysis of incident notifications with patient associations can help disseminate and increase reporting by raising citizen awareness about its importance. Although not every report leads to a sanitary measure, whether regulatory or not, a set of notifications arising from this civic responsibility, added to information reported by health services, may be able to generate consistent data and incite recommendations focused on reducing unnecessary harm (Notivisa, 2021a; Brasil, 2017). In addition, more investment in patient safety training of health professionals and the general public, as well as research development, can support patient safety improvement (WHO, 2011b) and citizens' compliance with incident reporting. This study had several limitations. First, information bias is highlighted given that data were obtained from a national database with incidents being reported voluntarily by patients or family members. Another limitation includes incomplete records and the notification form itself, which has pre-defined options and categories for safety incidents, potentially hindering responses. Furthermore, since underreporting is a possibility, the results obtained may not reflect the real picture of notifications in the system. A further limitation is the inability to use the results presented to make epidemiological estimates or for national monitoring of safety issues, since they depend on the level of awareness and topic knowledge of those who made the notification.

\section{Conclusion}

The present study showed the currently known distribution of incidents reported by citizens to the SNVS. Most notifications were related to HAIs, followed by medications or IV fluids. The majority of reported incidents resulting in death were due to HAIs, with a significant difference observed in the proportion of deaths in relation to age group. The study allows for learning from mistakes and can help managers, professionals, and researchers propose improvements in care systems, based on knowledge of the most frequent safety incidents reported by patients and family members. New challenges emerge from health initiatives already developed by the SNVS to promote patient participation in health care, including the opportunity for a reporting system. Nevertheless, it is necessary to expand strategies that encourage the notification of events by citizens as a complementary tool, supporting the promotion of a safety culture that values continuous learning from errors as a result of greater patient and family participation in health care.

\section{REFERENCES}

Agency for Healthcare Research and Quality, Patient Safety Network. Disclosure of errors. 2021. Available online at https://psnet.ahrq.gov/primer/disclosure-errors

Agoritsas, T., Bovier, P.A., Perneger, TV. 2005. Patient reports of undesirable events during hospitalization. J Gen Intern Med., v. 20, n. 10, pp. $922-8$

Agência Nacional de Vigilância Sanitária. 2017. Diretriz Nacional para Elaboração dePrograma de Gerenciamento do Uso deAntimicrobianos em Serviços de Saúde. Disponível em: https://www.gov.br/anvisa/ptbr/centraisdeconteudo/publicacoes/servicosdesaude/publicacoes

Aslani, P. et al. 2018. Consumer opinions on adverse events associated with medicines and vaccines. Patient Prefer Adherence, v.12, pp. 1383-92.

Baker, G.R.et al. 2004. The Canadian Adverse Events Study: the incidence of adverse events among hospital patients in Canada. CMAJ., v. 170, n. 11, pp.1678-86.

Brasil. Ministério da Saúde. 2013b. Documento de referência para o Programa Nacional de Segurança do Paciente. Ministério da Saúde; Fundação Oswaldo Cruz; Agência Nacional de Vigilância Sanitária. Brasília: Ministério da Saúde, pp 27-28.

Brasil. Agência Nacional de Vigilância Sanitária. 2017. Como posso contribuir para aumentar a segurança do paciente? Orientações aos pacientes, familiares e acompanhantes. ANVISA, Brasília, Brasil.

Brasil. Agência Nacional de Vigilância Sanitária. Resolução da Diretoria Colegiada. RDC n 63 de 25 de novembro de 2011. Dispõe sobre os requisitos de Boas Práticas de funcionamento para os serviços de saúde. Diário Oficial da União, Brasília, DF, 28 nov. 2011. 
Brasil. Agência Nacional de Vigilância Sanitária. Resolução da Diretoria Colegiada. RDC n 36 de 25 de julho de 2013 que institui ações para a segurança do paciente em serviços de saúde e dá outras providências. Diário Oficial da União, Brasília, DF, 26 jul.2013c.

Brasil. Ministério da Saúde. Portaria n 2616, de 12 de maio de 1998. Expede, na forma dos anexos I, II, III, IV e V, diretrizes e normas para a prevenção e o controle das infecções hospitalares. Diário Oficial da União, Brasília, DF, 13 mai. 1998.

Brasil. Ministério da Saúde. Portaria $n^{\circ} 529$ de $1^{\circ}$ de abril de 2013. Institui o Programa Nacional de Segurança do Paciente PNSP. . Diário Oficial da União, Brasília, DF, 23 abr. 2013a.

Canadian Patient Safety Institute. 2011. Canadian disclosure guidelines. Being Open with Patients and Families. cited 2021 Fev 24. . Available online at https://www.patientsafetyinstitute.ca/en/toolsResources/disclosure /Documents/CPSI\%20Canadian\%20Disclosure\%20Guidelines.pd $\mathrm{f}$

Cohen, M.R., Smetzer, J.L. 2018. ISMP Medication Error Report Analysis. Hosp Pharm., v.53, n.4, pp. 217-9.

European Commission. 2010. Patient Safety and Quality of Healthcare. Special Eurobarometer 327 European Opinion Research Group: Brussels, Belgium, pp. 5-10.

Flanagan, M.E.et al. 2011. A national collaborative for reducing health careassociated infections: Current initiatives, challenges, and opportunities. Am J Infect Control., v.39, n.8, pp.685-589.

Friedman, S.M. et al. 2008. Errors, near misses and adverse events in the emergency department: what can patients tell us? CJEM., v.10, n,5, pp. 421-7.

Goedecke,T.et al. 2016. Medication Errors: New EU Good Practice Guide on Risk Minimisation and Error Prevention. Drug Saf., v. 39, n.6, pp. 491-500.

Härmark, L., van Hunsel, F., Grundmark, B. 2015. ADR Reporting by the General Public: Lessons Learnt from the Dutch and Swedish Systems. Drug Saf., v.38, n.4, pp. 337-47.

Harrison, R. et al. 2015. The missing evidence: a systematic review of patients' experiences of adverse events in health care. Int J Qual Health Care, v. 27, n.6, pp. 424-42.

Hasegawa, T.et al. 2011. Patients' identification and reporting of unsafe events at six hospitals in Japan. Jt Comm J Qual Patient Saf., v. 37, n. 11, pp. 502-8.

Institute of Medicine. 2001. Crossing the Quality Chasm. A New Health System for the 21st Century. National Academy Press, Washington, EUA, 2001.

Janmano, P., Chaichanawirote, U., Kongkaew, C. 2018. Analysis of medication consultation networks and reporting medication errors: a mixed methods study. BMC Health Serv Res., v.18. n.221. Available online at https://doi.org/10.1186/s12913-0183049-2

Keers, R.Net al. 2014. Impact of interventions designed to reduce medication administration errors in hospitals: a systematic review. Drug Saf., v.37, n.5, pp.317-32.

Khan, A. et al. 2018. Engaging Families as True Partners During Hospitalization. J Hosp Med., v.13, n. 5, pp. 358-60.

Larizgoitia, I., Bouesseau, M.C., Kelley, E. 2013. WHO Efforts to Promote Reporting of Adverse Events and Global Learning. J Public Health Res., v.2, n.3, pp.e29.

Longtin, Y.et al. 2010. Patient participation: current knowledge and applicability to patient safety. Mayo Clin Proc., v.85, n. 1, pp.5362.

Maia, C.S.et al. 2018. Registry of adverse events related to health care that results in deaths in Brazil, 2014-2016. Epidemiol Serv Saude, v.27, n.2, pp. e2017320.

O'Hara, J.K. et al. 2018. What can patients tell us about the quality and safety of hospital care? Findings from a UK multicentre survey study. BMJ Quality \& Safety, v.27, pp.673-682.

Rodríguez-Suárez, J. et al. 2012b. Patient safety incidents notified by 22 mexican hospitals by way of the Sirais system.Rev CONAMED, v.17, n.2, pp.52-58.
Rodríguez-Suárez, J.et al. 2012a. Sistemas de notificación y registro de incidentes en México: Aprendizajes. Rev CONAMED, v.17, n.2, pp.81-86.

Santana, H.T. et al. 2020. The Protagonism of the Brazilian Health Regulatory System in the Evolution of Patient Safety in the Country: History, Dilemmas, and Current Challenges. J Patient Saf., v. 16, n. 4. pp. e260-e266.

Saturno, P.J. 2009. Estrategias para la participación del paciente en la mejora continua de la seguridad clínica. Rev Calid Asist., v.24, n.3, pp.124-130.

Shojania, K.G. et al. 2001. Making health care safer: a critical analysis of patient safety practices. Evid Rep Technol Assess Summ. . 43:i-x, pp.1-668.

Sistema de Notificações em Vigilância Sanitária. NOTIVISA. Módulo Cidadão. acesso em 23 mar 2021a. . Disponível em: http://www16.anvisa.gov.br/notivisaServicos/cidadao/notificacao/ evento-adverso/formulario.

Sistema Nacional de Notificações em Vigilância Sanitária NOTIVISA. acesso em 22 mar 2021b. . Disponível em: http://antigo.anvisa.gov.br/notivisa.

Villanueva-Egan, L.A., Rodríguez-Suárez, J., Lucero-Morales, J.J. 2012. Analysis of adverse events in hospital facilities in adults by age and gender. Rev CONAMED, v. 17, n. 3, pp.109-13.

Ward, J.K.et al. 2011. Patient involvement in patient safety: Protocol for developing an intervention using patient reports of organisational safety and patient incident reporting. BMC Health Serv Res., v. 11, pp.130.

Ward, J.K., Armitage, G. 2012. Can patients report patient safety incidents in a hospital setting? A systematic review. BMJ Qual Saf., v.21, n. 8, pp. 685-99.

Weingart, S.N. et al. 2005. What can hospitalized patients tell us about adverse events? Learning from patient-reported incidents. J Gen Intern Med., v.20, n. 9, pp. 830-6.

World Health Organization. 2002. Quality of care: patient safety report by the Secretariat. cited 2021 Mar 20. . Available online athttps://apps.who.int/iris/handle/10665/78467

World Health Organization. 2004. World Alliance for Patient Safety forward programme 2005. WHO press, Geneva, Switzerland.

World Health Organization. 2009a. Global priorities for patient safety research. WHO press, Switzerland.

World Health Organization. 2011b. WHO Multi-professional Patient Safety Curriculum Guide. WHO, Malta.

World Health Organization. 2016a. Guidelines on Core Components of Infection Prevention and Control Programmes at the National and Acute Health Care Facility Level. WHO press, Geneva, Switzerland

World Health Organization. 2016b. Medication Errors: Technical Series on Safer Primary Care. WHO press, Geneva, Switzerland.

World Health Organization. 2020. Global patient safety action plan 2021-2030: towards zero patient harm in health care. WHO press, Geneva, Switzerland

World Health Organization. 10 Facts on Patient Safety. cited 2021 Mar 23.Available online athttps://www.who.int/newsroom/facts-in-pictures/detail/patient-safetyWorld Health Conceptual .2010 .WHO Patient Safety \&Organization framework for the international classification for patient safety version 1.1: final technical report January 2009. World Health Organization. Available online at https://apps.who.int/iris/handle/10665/70882

World Health Organization. 2011a. Report on the burden of healthcare-associated infection worldwide: a systematic review of the literature. WHO press, Geneva, Switzerland.

World Health Organization. 2009b. WHO guidelines on hand hygiene in health care. First global patient safety challenge. Clean care is safer care. WHO press, Geneva, Switzerland. 